\title{
Effects of IL-8 Up-Regulation on Cell Survival and Osteoclastogenesis in Multiple Myeloma
}

Ana B. Herrero, ${ }^{* \dagger}$ Antonio García-Gómez, ${ }^{\ddagger}$ Mercedes Garayoa, ${ }^{* \dagger}$ Luis A. Corchete, ${ }^{* \dagger}$ José M. Hernández, Jesús San Miguel, ${ }^{\natural}$ and Norma C. Gutierrez ${ }^{* \dagger}$

\begin{abstract}
From the Hematology Department, * University Hospital of Salamanca, Biomedical Research Institute of Salamanca, Salamanca; the Cancer Research Center, ${ }^{\dagger}$ University of Salamanca, Salamanca; the Bellvitge Biomedical Research Institute, ${ }^{\ddagger}$ Barcelona; the Hematology Department, ${ }^{\S}$ General Hospital of Segovia, Segovia; and the University Clinic of Navarra, "Center of Applied Medical Research, Navarra Institute for Health Research, Pamplona, Spain
\end{abstract}

\author{
Accepted for publication \\ April 11, 2016. \\ Address correspondence to \\ Norma C. Gutierrez, M.D., \\ Ph.D., University Hospital of \\ Salamanca, Paseo de San \\ Vicente 58-182, 37007 Sala- \\ manca, Spain. E-mail: \\ normagu@usal.es.
}

\begin{abstract}
IL-8 promotes cancer cell growth, survival, angiogenesis, and metastasis in several tumors. Herein, we investigated the sources of IL-8 production in multiple myeloma (MM) and its potential roles in MM pathogenesis. We found that bone marrow cells from patients with MM secreted higher amounts of IL-8 than healthy donors. IL-8 production was detected in cultures of CD138 $8^{+}$plasma cells and CD138 ${ }^{-}$cells isolated from bone marrows of MM patients, and in three of seven human myeloma cell lines (HMCLs) analyzed. Interactions between MM and stromal cells increased IL-8 secretion by stromal cells through cell-cell adhesion and soluble factors. Interestingly, IL8 expression also increased in HMCLs, stromal cells, and osteoclasts after treatment with the antimyeloma drugs melphalan and bortezomib. In fact, the effect of bortezomib on IL-8 production was higher than that exerted by stromal-MM cell interactions. Addition of exogenous IL-8 did not affect growth of HMCLs, although it protected cells from death induced by serum starvation through a caspase-independent mechanism. Furthermore, IL-8 induced by stromal-MM cell interactions strongly contributed to osteoclast formation in vitro, because osteoclastogenesis was markedly reduced by IL-8-specific neutralizing antibodies. In conclusion, our results implicate IL- 8 in myeloma bone disease and point to the potential utility of an anti-IL-8 therapy to prevent unwanted effects of IL-8 up-regulation on survival, angiogenesis, and osteolysis in MM. (Am J Pathol 2016, 186: 2171-2182; http://dx.doi.org/10.1016/j.ajpath.2016.04.003)
\end{abstract}

Multiple myeloma (MM) is the second most common hematological malignancy, with an annual incidence of four new cases per 100,000 individuals. MM is characterized by the accumulation of immunoglobulin-secreting clonal malignant plasma cells within the bone marrow (BM) and the evidence of end-organ damage, including osteolytic bone lesions, hypercalcemia, renal disease, and anemia. $^{1-3}$

Interactions between MM cells and BM cells have been widely reported to increase tumor growth, survival, migration, and drug resistance of myeloma cells. ${ }^{1,4,5}$ These effects are mostly mediated by several cytokines, many of them induced by the interaction of myeloma cells with BM stromal cells (BMSCs). The network of cytokines includes several ILs (IL-1 $\beta$, IL-2, IL-3, IL-4, IL-6, IL-10, IL-11, IL15 , and IL-21), and other growth factors such as insulin-like growth factor-1, tumor necrosis factor- $\alpha$, transforming growth factor- $\beta$, vascular endothelial growth factor, and macrophage inflammatory protein- $1 \alpha$. Some of these soluble factors, such as transforming growth factor- $\beta$, IL-15, and IL-21, are produced and secreted by myeloma cells themselves. Others, like insulin-like growth factor-1, macrophage inflammatory protein- $1 \alpha$, and IL-6, are mainly produced by the cells of the microenvironment. ${ }^{1,6}$ Finally, some cytokines like VEFG or tumor necrosis factor- $\alpha$ are produced by both types of cells.

Supported in part by the Spanish Myeloma Network Program (RD12/ 0036/0058), Spanish Association for Cancer Research (GCB120981SAN), the INNOCAMPUS Program (CEI10-1-0010), Spanish MINECO-ISCIII (PI12/02591) and FEDER, Consejería de Educación from Junta Castilla y León (FIC335U14) and the Centers for Regenerative Medicine and Cellular Therapy from Castilla y León.

Disclosures: None declared. 
IL-6 is considered a major growth and survival factor for myeloma cells. ${ }^{1,6}$ It is up-regulated in BMSCs by either adhesion of MM cells or soluble factors. ${ }^{7-9}$ The function of IL-6 as a survival factor has been demonstrated by its ability to inhibit spontaneous apoptosis and that induced by different conditions, like serum deprivation, treatment with dexamethasone, or Fas cell-death receptor. ${ }^{10-13}$

IL-8, a member of the CXC chemokine family, was originally described as a neutrophil chemoattractant. ${ }^{14}$ This cytokine is normally produced by a wide range of cells, including lymphocytes, monocytes, endothelial cells, fibroblasts, hepatocytes, and keratinocytes. The overexpression of IL-8 in many tumors and cancer cell lines has led to investigation of its role in tumor progression. ${ }^{15-17}$ IL-8 promotes tumor growth, angiogenesis, and metastasis in a variety of human cancers. ${ }^{16,18-21}$ Moreover, production of IL-8 by breast cancer cells increases osteoclast formation, probably contributing to bone metastasis. ${ }^{22,23}$ In MM, BMSCs and endothelial cells from patients secrete higher amounts of IL- 8 than their healthy counterparts. ${ }^{24,25}$ However, the contribution of myeloma cells and their interaction with the microenvironment to IL-8 production has not been deeply analyzed. Regarding the role of IL- 8 in MM cell proliferation, two reports have been published with contradictory results. In one study, increased MM cell proliferation mediated by the presence of the chemokine was reported ${ }^{25}$ whereas no differences in proliferation rates were observed in the other. ${ }^{26}$

Herein, we investigated the sources of IL-8 production in $\mathrm{MM}$ and its potential role in MM pathogenesis. Our results showed that IL-8 was majorly induced on stromal cells after the interaction with MM cells, and was also up-regulated in both myeloma and stromal cells by treatment with antimyeloma drugs. The presence of recombinant IL-8 (rIL-8) affected neither growth of human myeloma cell lines (HMCLs) nor drug resistance. However, rIL-8 protected MM cells from cell death induced by serum starvation. More important, we also showed that IL- 8 produced by the interaction between MM cells and human mesenchymal stem cells (hMSCs) played a major role in osteoclastogenesis.

\section{Materials and Methods}

\section{Cells and Culture Conditions}

BM aspirates from healthy donors or patients with MM were obtained after written informed consent of participants. Aspirates were subjected to lysis to remove red blood cells, and resuspended in RPMI 1640-L-glutamine medium supplemented with $10 \%$ fetal bovine serum and antibiotics at an initial concentration of $7.5 \times 10^{5}$ cells $/ \mathrm{mL}$. Cells were grown at $37^{\circ} \mathrm{C}$ in a humidified atmosphere with $5 \% \mathrm{CO}_{2}$. Supernatants were collected after 48 hours of culture and stored at $-20^{\circ} \mathrm{C}$ until use. When necessary, $\mathrm{CD} 138^{+}$plasma cells were isolated (purity $>95 \%$ ) from the bone marrow samples using the AutoMACS automated separation system (Miltenyi-Biotec, Bergisch Gladbach, Germany).

The HMCLs NCI-H929 and MM.1S were acquired from ATCC (Manassas, VA), and the rest of the HMCLs from Deutsche Sammlung von Mikroorganismen und Zellkulturen (Braunschweig, Germany). HMCLs were cultured in RPMI medium as described above. The human BM mesenchymal stromal cell line-TERT (hMSC-TERT) was a generous gift from Dr. Campana (St. Jude Children's Research Hospital, Memphis, TN). ${ }^{27}$ It was cultured in DMEM low-glucose supplemented with antibiotics and 10\% fetal bovine serum. The MM.1S-luc cell line was kindly provided by Dr. Mitsiades (Dana-Farber Cancer Institute, Boston, MA), whereas RPMI-8226-luc was lentivirally transduced to express firefly luciferase. $^{28}$

\section{Measurement of IL-8 in Culture Medium}

MM.1S, H929, JJN3, OPM2, U266, RPMI-8226, and IM9 $\left(2 \times 10^{5}\right.$ cells $\left./ \mathrm{mL}\right)$ were cultured for 3 days. The supernatants were collected and analyzed for IL-8 expression using a commercially available enzyme-linked immunosorbent assay (ELISA) kit (R\&D Systems, Minneapolis, MN), according to manufacturer's instructions. IL- 8 concentrations $<2 \mathrm{pg} / \mathrm{mL}$ were considered undetectable.

\section{Co-Cultures of HMCLs with hMSC-TERT Cells}

hMSC-TERT cells $\left(1 \times 10^{5}\right.$ cells $)$ and HMCLs $\left(2 \times 10^{5}\right.$ cells) were co-cultured or cultured independently in $800 \mu \mathrm{L}$ of RPMI medium for 24 hours. In the experiments designed to identify which cell type was producing IL-8 in the coculture system, either the h-MSC-TERT cells or the HMCLs were mildly fixed by incubation with $1 \%$ paraformaldehyde for 10 minutes, extensively washed with phosphate-buffered saline, and co-cultured as described above. When physical contact in the co-culture was to be avoided, $100 \mu \mathrm{L}$ of medium containing $5 \times 10^{4} \mathrm{MM}$ cells was added to the upper chamber of a 24-transwell plate (0.4$\mu \mathrm{m}$ pore size; Corning-Costar, Corning, NY) that contained in the lower chamber $600 \mu \mathrm{L}$ of medium with adhered hMSC-TERT cells $\left(1.2 \times 10^{5}\right.$ cells $)$. The system physically separated HMCLs from hMSC-TERT cells but allowed interaction between them by soluble factors. The supernatants were collected after 48 hours of culture and measured for IL-8 secretion by ELISA. Cells were recovered and used for RNA extraction.

\section{Quantitative RT-PCR Analysis}

To analyze $I L-8$ expression, total RNA was reverse transcribed to cDNA using a cDNA Reverse Transcription Kit from Applied Biosystems (Foster City, CA). Quantitative RT-PCR (RT-qPCR) was performed using iQ SYBR Green Supermix kit (Bio-Rad, Hercules, CA), the iQ5 PCR detection system, and the following gene-specific primers: 
IL-8, 5'-GTGCAGTTTTGCCAAGGAGT-3' (forward) and 5'-CTCTGCACCCAGTTTTCCTT-3' (reverse); GAPDH, $5^{\prime}$-GGGTGGAATCATATTGGAACATGTA-3' (forward) and $5^{\prime}$-CAGGGCTGCTTTTAACTCTGGTAA-3' (reverse). Relative expression of IL-8 was normalized to GAPDH using the $2^{-\Delta \mathrm{Ct}}$ method, where $\Delta \mathrm{Ct}=\mathrm{Ct}_{I L-8}-\mathrm{Ct}{ }_{G A P D H}$.

\section{Reagents}

rIL-8, anti-IL-8, and anti-IL-6 antibodies were purchased from R\&D Systems (Minneapolis, MN). rIL-6 was obtained from PeproTech (London, UK). Melphalan and dexamethasone were obtained from Sigma-Aldrich (St. Louis, MO), and bortezomib (Velcade) was obtained from the Pharmacy of the University Hospital of Salamanca. Anti-Fas was obtained from Upstate-Millipore (Billerica, MA). Macrophage colony-stimulating factor (M-CSF) and receptor activator of NF- $\kappa$ B ligand (RANKL) were supplied by PeproTech. BAY 11-7082 and PS-1145 were purchased from Santa Cruz Biotechnology (Dallas, TX).

\section{Cell Proliferation and Cell Viability Assays}

Cell proliferation in the presence of rIL-8 or IL-8 blocking antibodies was determined by cell counting after 48 or 72 hours of culture. Alternatively, cell growth was monitored by bromodeoxyuridine incorporation, quantitation of ATP (CellTiter-Glo; Promega, Madison, WI), or measuring luminescence of RPMI-8226-luc and MM.1S-luc HMCLs. Cell viability in the presence of drugs was assessed by the MTT assay. Cell survival in the absence of serum and in the presence of rIL-8, rIL-6, or the corresponding blocking antibodies was determined by trypan blue exclusion and apoptosis by annexin $\mathrm{V}$-isothiocyanate/propidium iodide double staining, according to the manufacturer's procedure (Immunostep, Salamanca, Spain). Caspase-3 activity was determined using a colorimetric assay kit provided by Promega.

\section{In Vitro Osteoclast Formation Assay}

Peripheral blood mononuclear cells were isolated from blood of healthy donors after centrifugation with FicollPaque (GE Healthcare, Uppsala, Sweden). Cells were resuspended at $1.5 \times 10^{6}$ cells $/ \mathrm{mL}$ in $\alpha$-minimum essential medium containing $10 \%$ fetal bovine serum, and cultured overnight in 96-well plates $(100 \mu \mathrm{L}$ of cell suspension per well). Adherent cells were then cultured in the same medium in the presence of $25 \mathrm{ng} / \mathrm{mL} \mathrm{M}-\mathrm{CSF}$ as a negative osteoclastogenic control; addition of $50 \mathrm{ng} / \mathrm{mL}$ recombinant RANKL was assayed as a positive control for osteoclast formation. Conditioned medium (CM) from IM9-hMSCTERT direct co-cultures was assayed at 1:4 dilution, and rIL-8 or IL-8-blocking antibodies were assayed at $50 \mathrm{ng} /$ $\mathrm{mL}$ and $25 \mu \mathrm{g} / \mathrm{mL}$, respectively. CM contained $10 \pm 0.3 \mathrm{ng} /$ $\mathrm{mL}$ of IL-8, as measured by ELISA. Anti-IL-8 was added to some of the CM-containing wells. The concentration used, $25 \mu \mathrm{g} / \mathrm{mL}$, completely blocked the IL- 8 found in CM, as determined by ELISA. Medium was replaced twice a week, and cultures were terminated on day 21. Plates were stained for tartrate resistance acid phosphatase (Sigma), and multinucleated tartrate resistance acid phosphatase-positive cells ( $\geq 3$ nuclei) were counted as osteoclast.

\section{Statistical Analysis}

Differences between the data were assessed for statistical significance using the Student's unpaired two-tailed $t$-test with the Simfit statistical software version 7.0.5 (Manchester, UK).

\section{Results}

\section{Expression of IL-8 in MM and Normal Plasma Cells}

Using microarray expression data from our previous studies (http://www.ncbi.nlm.nih.gov/geo; Gene Expression Omnibus accession number GSE47552), IL-8 mRNA was found to be up-regulated in $\mathrm{CD} 138^{+}$PCs isolated from patients with MM compared with normal plasma cells (Figure 1A). ${ }^{29}$ In contrast, the expression of IL-6 mRNA was similar in normal plasma cells and multiple myeloma plasma cells (MMPCs). Overexpression of IL-8 in CD138 ${ }^{+}$ PCs from several MM patients was verified by RT-qPCR (Figure 1B). Then, secretion of IL-8 was measured by ELISA in culture supernatants from BM cells obtained from $15 \mathrm{MM}$ patients and 10 healthy donors. We found that BM cells from MM patients secreted statistically significant higher amounts of IL-8 than those from healthy donors, whose IL-8 levels were nondetectable in most of the cases (Figure 1, C and D). However, no correlation was found between levels of IL- 8 and the percentage of PCs present in the BM of each patient. In fact, BMs with the highest proportion of PCs (>80\%) secreted lower amounts of IL-8 than others with lower PC infiltration. This result suggested that although high levels of IL-8 were associated with the presence of MMPCs, these cells might not be the main producers in the BM.

Direct Cell Contact between MMPCs and the Remaining BM Cells Increases IL-8 Secretion

Interactions between $\mathrm{MM}$ cells and BM cells have been shown to enhance the production of $\mathrm{IL}-6^{10}$ and other angiogenic factors, such as vascular endothelial growth factor or hepatocyte growth factor. ${ }^{8,30,31}$ To determine whether IL-8 was also induced as a consequence of the interaction between myeloma cells and the remaining BM cell populations, IL-8 levels were quantified by ELISA in the 24-hour culture supernatant collected from the same number of $\mathrm{CD}_{138^{+}}$MMPCs and $\mathrm{CD} 138^{-}$cell fraction cultured separately or together (direct co-culture) (Figure 2). The assays performed in three different patients showed that 

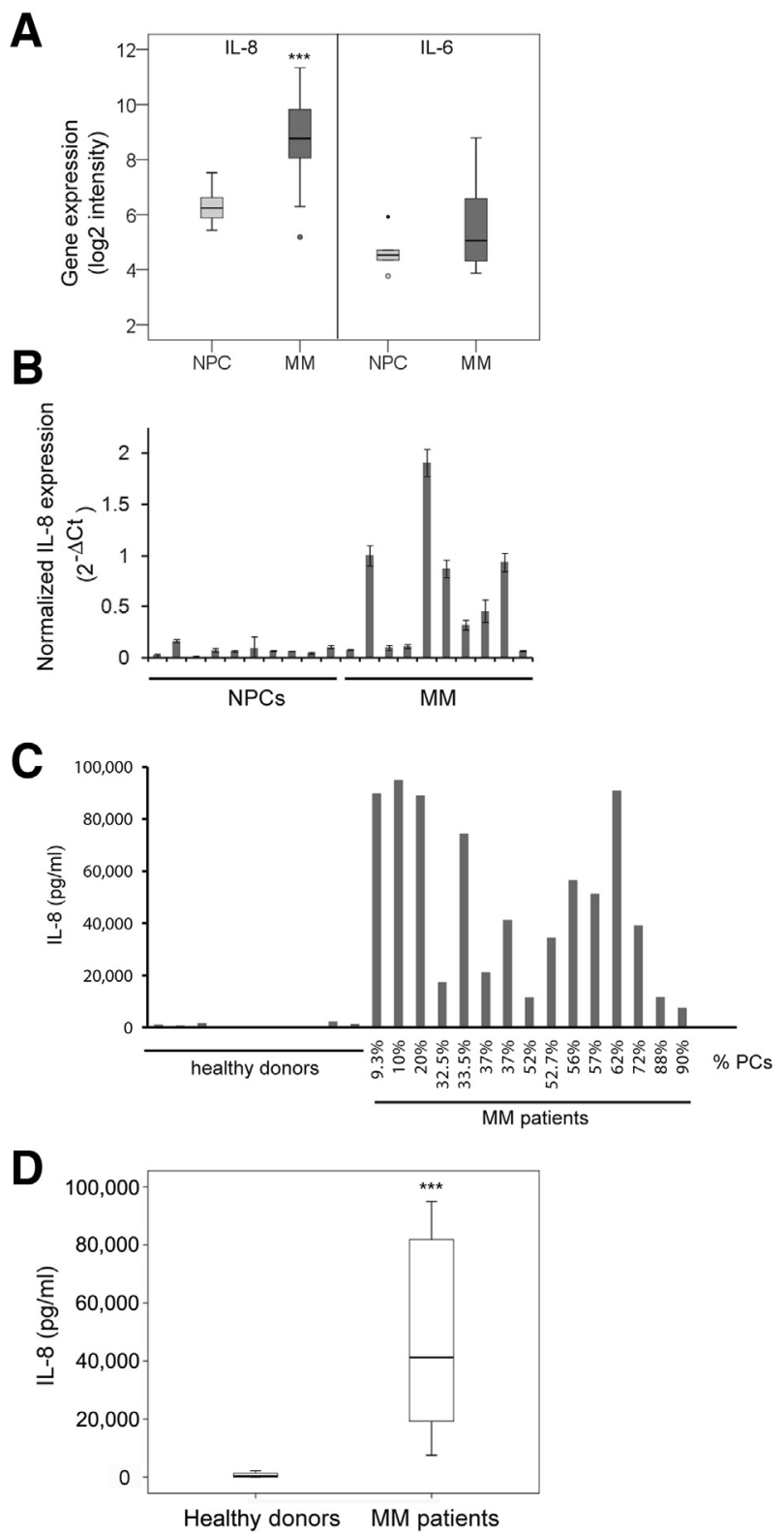

Figure 1 Expression and secretion of IL-8 in multiple myeloma (MM). A: IL8 and IL6 gene expression by microarray analysis in plasma cells (PCS) derived from healthy donors or MM patients (CD138 ${ }^{+}$-isolated cells). Gene expression was determined by microarray analysis. Data are from five normal PCs (NPCs) and PCs from 74 MM samples. B: Expression levels of IL-8 quantified by quantitative RT-PCR. Expression of IL-8 was normalized to glyceraldehyde-3-phosphate dehydrogenase and presented as $2^{-\Delta \mathrm{Ct}}$. C: IL-8 levels, assessed by enzyme-linked immunosorbent assay, in culture supernatants of bone marrow cells obtained from healthy donors and patients with MM. Percentage of PC infiltration for each sample is indicated. D: Box plot representation of IL-8 levels showed in C. Data are expressed as means $\pm \mathrm{SD}(\mathbf{A}) .{ }^{*} * P<0.001$.

CD138 ${ }^{-}$cells secreted higher amounts of IL-8 than CD138 ${ }^{+}$ cells, suggesting that $\mathrm{BM}$ cell populations other than myeloma cells were the major IL-8 producers. In addition, IL-8 levels were further increased after co-culture of both types of cells, indicating that $\mathrm{CD} 138^{-}$cells, $\mathrm{CD} 138^{+}$cells, or both favored the production of IL-8 when cultured together.
Adhesion of MM Cell Lines to Mesenchymal Stromal Cells Triggers IL-8 Secretion

ELISA quantification of IL-8 in the CM from different HMCLs showed that IL-8 production was low in IM9, JJN3, and RPMI-8226, and undetectable in the CM from all other HMCLs (Figure 3A).

To analyze whether adherence of HMCLs to stromal cells induced IL-8 secretion, four MM cell lines (IM9, RPMI8226, JJN3, and U266) were cultured alone or together with the stromal hMSC-TERT cell line. IL-8 secretion increased approximately threefold to fourfold when RPMI-8226, JJN3, or U266 were in contact with the stromal cell line, and nearly 30-fold when the IM9 cell line was co-cultured with hMSCTERT cells compared with hMSC-TERT cells alone (Figure 3B). To determine the identity of the cells that increased IL-8 production, HMCLs or hMSC-TERT cells were fixed with paraformaldehyde before the co-cultures,
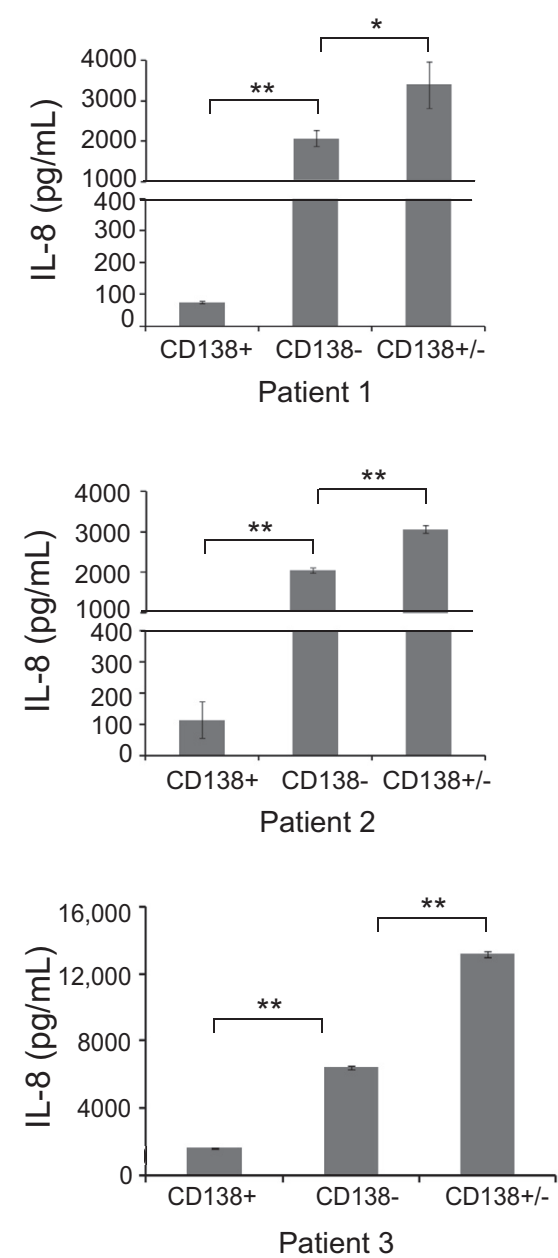

Figure 2 Interactions between multiple myeloma (MM) cells and stromal cells induce IL-8 overproduction. CD138 ${ }^{+}$plasma cells and CD138 cells were isolated from three patients with MM using immunomagnetic beads. CD138 ${ }^{+}$cells $\left(1 \times 10^{5}\right)$ and $\mathrm{CD}_{138^{-}}$cells $\left(1 \times 10^{5}\right)$ were cultured independently or together in $200 \mu \mathrm{L}$ of culture medium. IL-8 was measured after 24 hours of culture by enzyme-linked immunosorbent assay. Data are expressed as means \pm SD from duplicates. ${ }^{*} P<0.05,{ }^{* *} P<0.01$. 
A

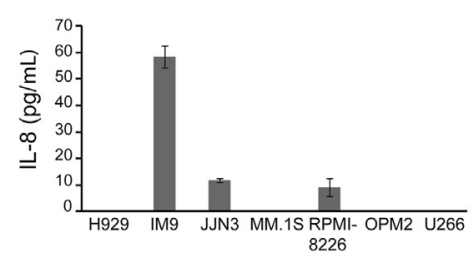

C

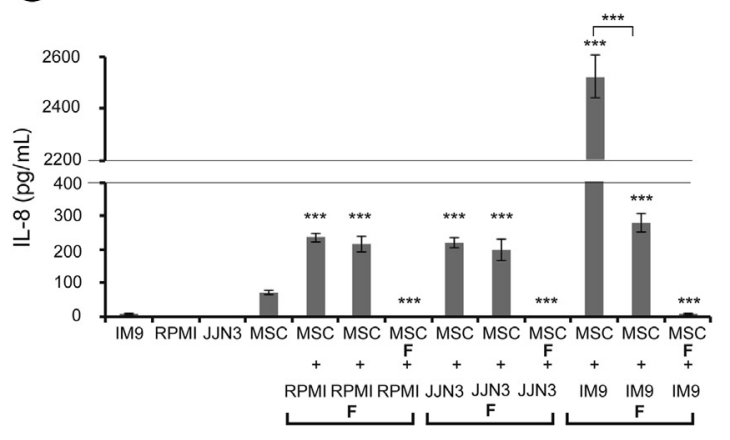

D

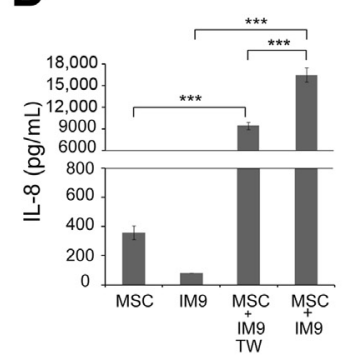

E
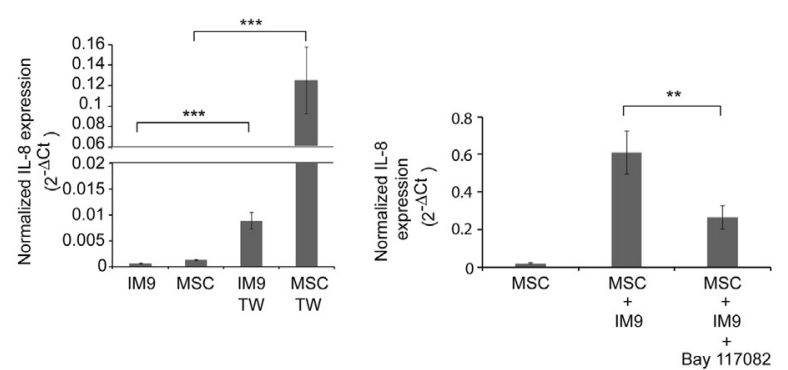

Figure 3 Interactions between human myeloma cell lines (HMCLs) and stromal cells increase IL-8 secretion. A: IL-8 levels in culture supernatants of HMCLs measured by enzyme-linked immunosorbent assay (ELISA). B: Cells from the indicated HMCLs and human bone marrow mesenchymal stromal cell line-TERT (hMSC-TERT) cells (MSC) were cultured independently or together in $800 \mu \mathrm{L}$ of culture medium. IL-8 levels were determined after 24 hours of culture by ELISA (compared with MSC). C: Same as B but with hMSCTERT cells or HMCLs mildly fixed with paraformaldehyde (indicated as F) (compared with MSC). D: IL-8 levels in conditioned media from hMSC-TERT cells, IM9 cells, or direct or transwell (TW) co-cultures. E: IL-8 expression levels in hMSC-TERT or IM9 cells quantified by quantitative RT-PCR (RT-qPCR) in the specified conditions. F: hMSC-TERT cells $\left(4 \times 10^{5}\right)$ per well were plated in 6-well dishes and allowed to form an adherent monolayer over 24 hours. Then, hMSC-TERT cells and IM9 cells $\left(6 \times 10^{5}\right)$ were pretreated 3 hours with nonlethal concentrations of BAY 11-7082 (5 and $3 \mu \mathrm{mol} / \mathrm{L}$, respectively) and cultured independently or co-cultured with $3 \mu \mathrm{mol} / \mathrm{L}$ BAY 11 7082 for an additional 24 hours in RPMI medium. Finally, multiple myeloma (MM) cells were mechanically detached from the hMSC-TERT, leaving the monolayer undisturbed, and IL-8 expression was quantified in hMSC-TERT cells by RT-qPCR. Data are expressed as means \pm SD $(\mathbf{A}, \mathbf{B}$, and $\mathbf{D}-\mathbf{F})$. $n=3$ independent experiments $(\mathbf{A}-\mathbf{F}) .{ }^{* *} P<0.01$, $* * * P<0.001$. according to a protocol previously described for other cytokines or growth factors. ${ }^{8,32}$ Fixation of hMSC-TERT cells before co-culture with RPMI-8226, JJN3, or IM9 abolished IL-8 production (Figure 3C). In contrast, fixation of RPMI-8226 or JJN3 did not significantly inhibit IL-8 overproduction induced by the co-culture. These results indicated that stromal cells were the major source of IL- 8 , and that IL-8 secretion, when stromal cells were co-cultured with RPMI8226 or JJN3, was mainly induced by cell-cell adhesion. However, fixation of IM9 cells markedly reduced IL-8 production induced by the co-culture with hMSC-TERT cells, which suggested that soluble factors might also be contributing to IL-8 overexpression in addition to cell-cell adhesion.

\section{Soluble Factors Contribute to IL-8 0verproduction in Co-Cultures of IM9 with hMSC-TERT Cells}

To further investigate the IL-8 secretion induced by the interaction of IM9 with hMSC-TERT cells, co-cultures were established using transwell inserts, which prevent contact of both types of cells but allow the diffusion of soluble factors.
Secretion of IL-8 was found highly increased when cells were co-cultured in the absence of physical contact, although to a lesser extent than that observed by direct cellcell contact (Figure 3D). These results confirmed that induction of IL-8 in co-cultures of IM9 with hMSC-TERT cells was dependent on both cell-cell adhesion and soluble factors. To identify the cells responsible for the increased IL- 8 production in the absence of physical contact, IL- 8 mRNA expression was quantified in IM9 and stromal cells separately recovered after the transwell co-culture (Figure 3E). IL-8 mRNA levels were up-regulated in both IM9 and hMSC-TERT cells as a result of the interaction between the two cell types in the absence of cell contact, although induction was much higher in hMSC-TERT cells.

It has been previously shown that induction of IL-6 secretion from BMSCs triggered by MM cell adhesion is mediated through NF- $\kappa \mathrm{B} .{ }^{33}$ Likewise, IL-8 production by stromal cells in the presence of BM culture supernatants from MM patients was dependent on NF- $\kappa \mathrm{B}$ signaling. ${ }^{26}$ So we expected that this transcription factor would also be implicated in IL-8 overexpression observed in hMSC-TERT 
cells co-cultured with IM9. Thus, we found that the NF- $\kappa$ B inhibitor BAY 11-7082 partially blocked the IL-8 up-regulation observed in hMSC-TERT cells after the co-culture with IM9 cells, which confirmed that NF- $\kappa \mathrm{B}$ was involved in the production of IL- 8 in hMSC-TERT cells triggered by MM cell interactions (Figure 3F).

\section{IL-8 Secretion Is Induced by Treatment with Antimyeloma Drugs}

It has been described that expression of IL- 8 is induced by treatment with paclitaxel in non-small cell lung cancer ${ }^{34}$ and ovarian carcinoma cells. ${ }^{35}$ Likewise, increased expression of IL-8 mRNA has been recently reported after treatment of MM cells with lenalidomide. ${ }^{36}$ These observations prompted us to investigate the effect of other antimyeloma drugs in IL-8 secretion. We found that treatment of RPMI-8226 and IM9 cells with bortezomib or melphalan increased IL-8 expression (Figure 4A). However, IL-8 up-regulation was found to be NF- $\kappa \mathrm{B}$ independent because treatment of these HMCLs with the NF- $\kappa$ B inhibitor BAY 11-7082, at the inhibitory concentration of $5 \mu \mathrm{mol} / \mathrm{L},{ }^{37,38} \mathrm{did}$ not suppress either the bortezomib- or the melphalan-induced IL-8 expression (Figure 4B). Similar results were obtained with
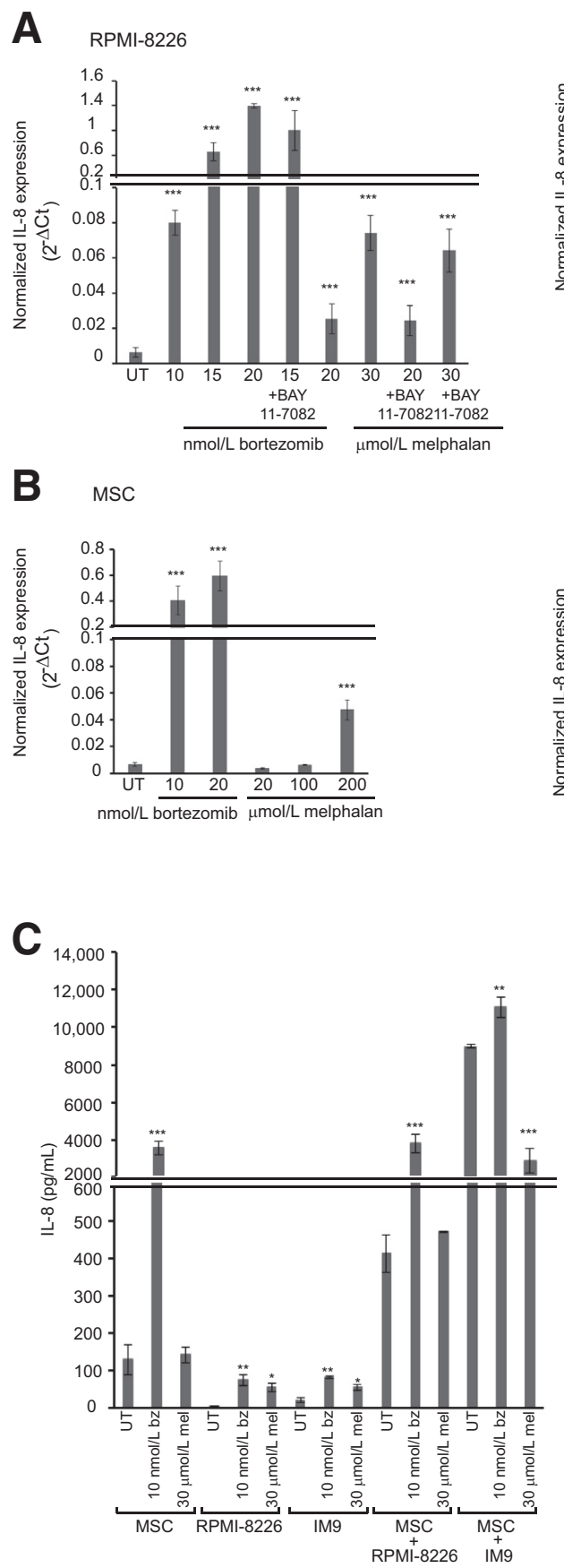

IM9
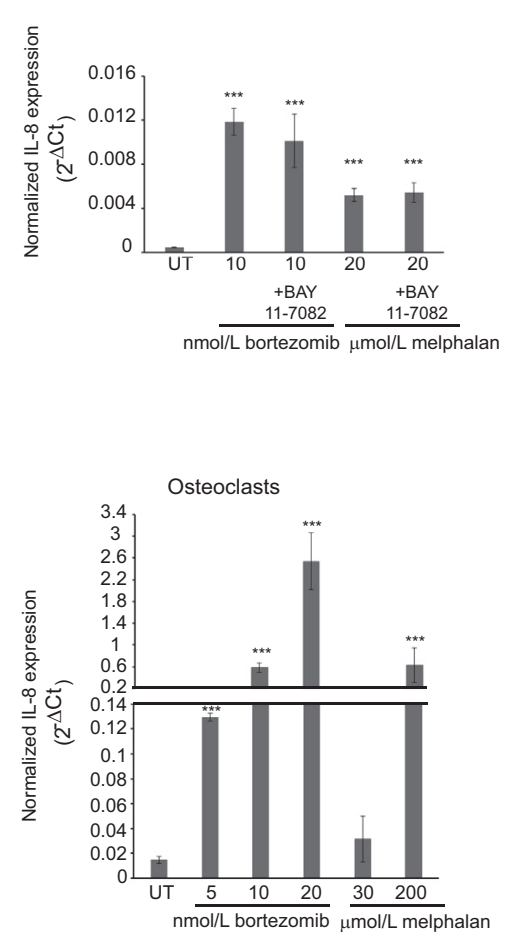

D

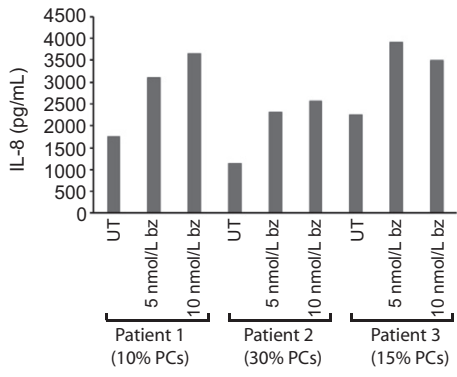

Figure 4 Up-regulation of IL-8 by treatment with bortezomib (bz) and melphalan (mel). A: IL-8 expression in RPMI-8226 and IM9 cells pretreated for 12 hours with BAY 11-7082 or left untreated before 24 hours incubation with the indicated doses of bortezomib and melphalan. BAY 11-7082 was used at $5 \mu \mathrm{mol} / \mathrm{L}$ in RPMI-8226 cells and at $3 \mu \mathrm{mol} / \mathrm{L}$ in IM9 cells. B: IL-8 expression in human bone marrow mesenchymal stromal cell line-TERT (hMSC-TERT) cells (MSC) and osteoclasts after 24 hours of culture in the absence (UT) or the presence of the indicated drugs. 0steoclasts were obtained from peripheral blood mononuclear cells after 21 days of culture in osteogenic medium containing $25 \mathrm{ng} / \mathrm{mL}$ macrophage colony-stimulating factor and $50 \mathrm{ng} / \mathrm{mL}$ receptor activator of NF- $\kappa \mathrm{B}$ ligand. C: Human myeloma cell lines and hMSC-TERT cells (MSC) were cultured independently or co-cultured in $800 \mu \mathrm{L}$ of culture medium in the absence (UT) or the presence of the indicated drugs. IL-8 levels were determined after 24 hours of culture by enzyme-linked immunosorbent assay. D: IL8 secretion by bone marrow cells isolated from three multiple myeloma (MM) patients treated or untreated (UT) with bortezomib for 24 hours. Data are expressed as means $\pm \mathrm{SD}(\mathbf{C}) . n=3$ independent experiments (C). ${ }^{*} P<0.05,{ }^{* *} P<0.01,{ }^{* * *} P<0.001$ versus UT cells. PC, plasma cell. 
$20 \mu \mathrm{mol} / \mathrm{L}$ specific IKK $\beta$ inhibitor PS-1145 ${ }^{37}$ (data not shown). We then explored whether stromal cells and osteoclasts, as components of the BM microenvironment, also increased IL-8 expression after treatment with the antimyeloma drugs. The presence of these drugs clearly induced IL-8 expression in the two cell types, although IL-8 induction caused by melphalan required higher doses than those used in MM cells (Figure 4B). Next, we analyzed IL-8 secretion in MM cell lines and in the stromal cell line hMSC-TERT cultured alone or co-cultured in the absence or the presence of bortezomib and melphalan (Figure 4C). We observed that bortezomib increased IL-8 secretion by MM cells and stromal cells when cultured alone, whereas melphalan at $30 \mu \mathrm{mol} / \mathrm{L}$ only induced IL-8 overexpression in MM cells, in accordance with the RT-qPCR data. Interestingly, we found that IL-8 secretion significantly augmented in bortezomib-treated co-cultures compared with those left untreated, indicating that the effect of this drug was higher than the effect of the co-culture on IL-8 production. Therefore, bortezomib induced IL-8 overexpression in hMSC-TERT cells and MM cells cultured separately or co-cultured. To support this finding in an in vivo setting, we also analyzed the effect of bortezomib on IL-8 secretion of $\mathrm{BM}$ cells isolated from three MM patients. BM cells clearly overexpressed IL-8 after treatment with the drug (Figure 4D).

\section{rIL-8 Protects MM Cells from Cell Death Induced by Serum Starvation through a Caspase-Independent Mechanism}

IL-8 has previously been reported to function as an autocrine growth factor for different normal and tumor cells. ${ }^{39-41}$ However, the role of IL-8 in MM cell proliferation is controversial. ${ }^{25,26} \mathrm{We}$ found that neither rIL-8 addition nor anti-IL-8 neutralizing antibodies affected cell proliferation of HMCLs as measured by cell counting (Figure 5A), bromodeoxyuridine incorporation, ATP quantification, or when the effect of rIL-8 or anti-IL-8 was assayed in RPMI-8226-luc and MM.1S-luc cells (data not shown). Similarly, addition of rIL-8 did not stimulate growth of myeloma cells even at low serum concentration (1\%) (data not shown).

Previous studies have demonstrated that IL-6 protects myeloma cells from cell death induced by treatment with antimyeloma drugs, from spontaneous and Fas-mediated apoptosis, as well as from cell death induced by serum starvation. ${ }^{10-13}$ We first investigated the effects of IL-8 on MM cell sensitivity to melphalan in RPMI-8226 (Figure 5B), MM.1S, JJN3, and IM9 cell lines (data not shown). Addition of rIL-8 did not affect cell death induced by melphalan (Figure 5B), even when the amounts of rIL-8 added exceeded those induced by the treatment (Figure 4A). On the other hand, treatment with anti-IL-8 neutralizing antibodies had no effect on cell death induced by the drug (Figure 5B). No protection against cell death was observed after treatment with different concentrations of bortezomib, dexamethasone, Fas ligand, or when spontaneous cell death was analyzed (data not shown). However, we observed that rIL-8 clearly prevented cell death induced by serum starvation in a similar way to IL-6, which was used as a positive control (Figure 5C). As expected, cell death protection was abrogated by addition of anti-IL-6 or anti-IL-8 neutralizing antibodies (Figure 5C). When apoptosis was analyzed using annexin $\mathrm{V} /$ propidium iodide staining, we found that addition of rIL-8 clearly protected MM cells from apoptotic cell death induced by serum starvation (Figure 5D). Interestingly, caspase 3 was activated after serum deprivation, even when rIL-8 was added to the media (Figure 5E). These results indicated that IL-8 protected HMCLs from apoptosis induced by serum deprivation via a caspaseindependent mechanism.

\section{rIL-8 Stimulates Growth of 0steoclast Precursors and IL-8 Induced by the Interaction of MM Cells with Stromal Cells Strongly Contributes to Osteoclast Formation in Vitro}

To analyze the role of IL-8 in osteoclastogenesis, we first investigated whether it influenced the growth of osteoclast precursors using peripheral blood mononuclear cells cultured with M-CSF in the absence or presence of different concentrations of rIL-8. After 7 days of culture, cell density was increased according to the concentrations of the chemokine (Figure 6A), which was corroborated measuring proliferation by the MTT assay (Figure 6B).

To ascertain the relative contribution of IL- 8 induced by the interaction of MM cells with stromal cells to osteoclast differentiation, CM from IM9-hMSC-TERT co-cultures, with and without IL-8 neutralizing antibody, was added to human peripheral blood mononuclear cells cultured in the presence of M-CSF. We found that the CM from the co-culture induced osteoclast formation (Figure 7A), as also did rIL-8 (Figure 7B), whereas anti-IL-8 antibody significantly reduced the number of osteoclasts provoked by the CM (Figure 7A). Osteoclasts induced by RANKL or IL-8 are shown in Figure 7C.

\section{Discussion}

We showed that interactions between myeloma and stromal cells triggered IL-8 overexpression. IL-8, induced in stromal cells by adhesion of MM cells and also by soluble factors, increased myeloma cell survival in serum starvation conditions and highly contributed to osteoclast formation. Moreover, we found that treatment with antimyeloma drugs also stimulated IL-8 overexpression.

Production of IL- 8 by cancer cells has been shown in melanoma, colon carcinoma, and liver and pancreatic cell lines. ${ }^{39,42-44}$ Herein, we showed using RT-qPCR that MM 
A

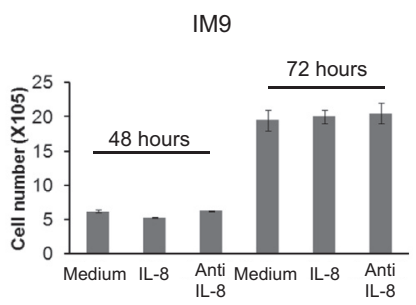

B

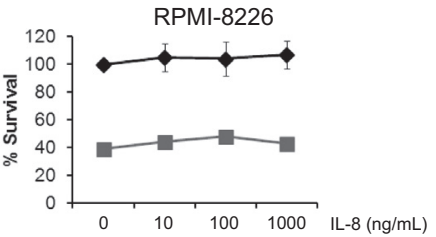

C

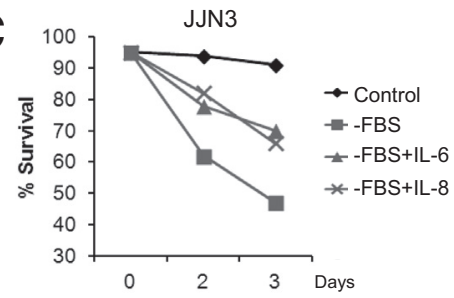

D

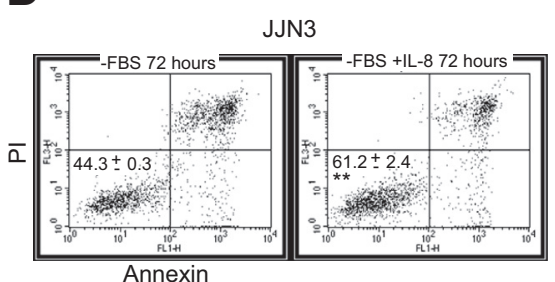

Annexin
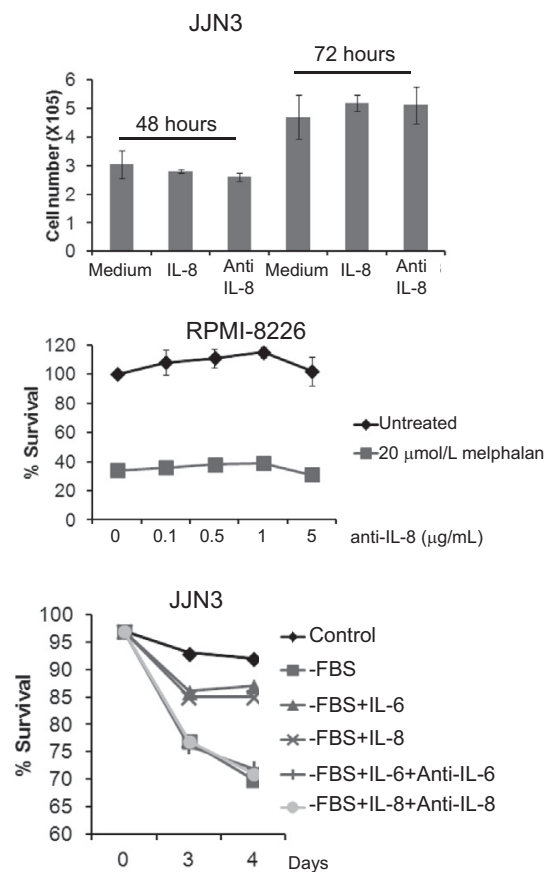

H929

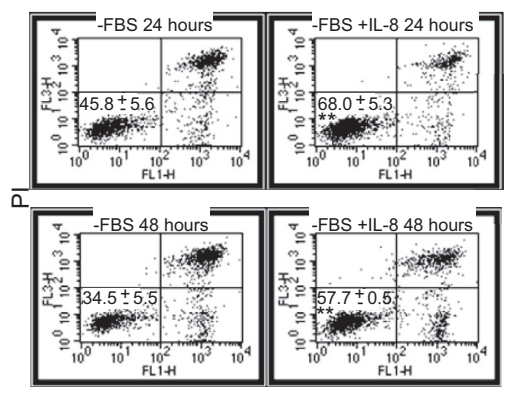

Annexin

E

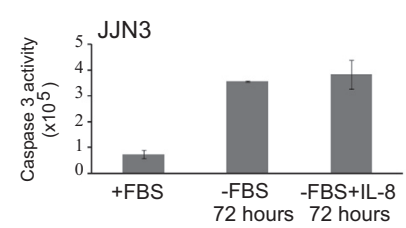

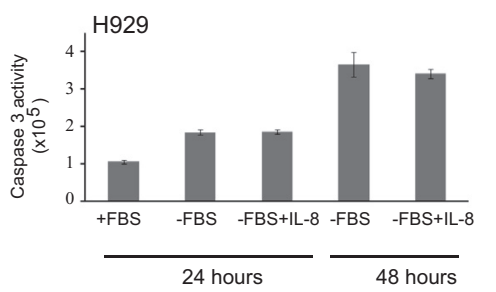

Figure 5 Recombinant IL-8 (rIL-8) affects neither the growth rate of multiple myeloma (MM) cells nor their resistance to antimyeloma drugs, but protects them from cell death induced by serum starvation. A: Cell growth of IM9 and JJN3 cell lines. Cells were plated at $5 \times 10^{4}$ cells $/ \mathrm{mL}$ in 24-well plates and cultured with medium alone or medium containing $100 \mathrm{ng} / \mathrm{mL} \mathrm{rIL}-8$ or $5 \mu \mathrm{g} / \mathrm{mL}$ anti-IL-8. Cell number was determined after 48 and 72 hours of culture. Values correspond to cell number. B: Survival of RPMI8226 cells to melphalan after 72 hours of culture in the presence of IL-8 (left) or anti-IL-8 (right) neutralizing antibodies assessed by MTT. C: Cells were plated at $1 \times 10^{5}$ cells $/ \mathrm{mL}$ in serum-free medium, and survival was determined at indicated times by trypan blue exclusion. Recombinant IL-6, rIL-8, or the corresponding neutralizing antibodies were used when indicated at $100 \mathrm{ng} / \mathrm{mL}$ (IL-6 and IL-8) or $5 \mu \mathrm{g} / \mathrm{mL}$ (IL-6 or IL-8 neutralizing antibodies). D: Cell death in JJN3 and H929 cells determined by annexin/ propidium iodide (PI) double staining after 72 hours of culture in serum-free medium and in the same medium supplemented with $100 \mathrm{ng} / \mathrm{mL} \mathrm{rIL}-8$. Percentages of annexin ${ }^{-} / \mathrm{PI}^{-}$(live cells) are given. Representative experiments are shown. E: Caspase 3 activation in JJN3 and $\mathrm{H} 929$ at the indicated times of culture in serum-free medium in the absence or in the presence of $100 \mathrm{ng} / \mathrm{mL}$ rIL-8. Data are expressed as means \pm SD (A and $\mathbf{D}) . n=3$ independent experiments (D). ${ }^{* * P}<0.01$ versus untreated cells. FBS, fetal bovine serum. cells isolated from several patients expressed higher levels of IL- 8 than those isolated from healthy donors, confirming the overexpression of this chemokine in primary MM cells previously observed by expression microarrays. ${ }^{29,45}$ Secretion of IL-8 was detected in PCs isolated from patients with MM and in some HMCLs, and interactions between stromal and myeloma cells significantly increased the production of this chemokine. Stromal cells were the major source of IL-8, as also described for vascular endothelial growth factor and hepatocyte growth factor, ${ }^{30,31}$ which highlights the importance of these cells in producing angiogenic factors. In IM9/ hMSC-TERT co-cultures, IL-8 secretion was mainly increased in stromal cells by both cell adhesion and soluble factors, which is analogous to the secretion pattern described for IL-6. ${ }^{8}$ Levels of IL- 8 transcripts also increased in IM9 cells after co-cultures established in the absence of physical contact. These findings are in agreement with the results described in non-small cell lung cancer, in which tumor/stromal co-cultures induced IL-8 production, in pulmonary fibroblast and in certain non-small cell lung cancer cell lines. ${ }^{46}$ According to previous published results for IL-6 and IL-8, we found that IL-8 up-regulation in stromal cells because of interaction with IM9 cells was partially mediated by the transcription factor $\mathrm{NF}-\kappa \mathrm{B} .{ }^{26,33}$

Interestingly, IL-8 expression was also induced by treatment of MM cells, stromal cells, and osteoclasts with 


\section{A}

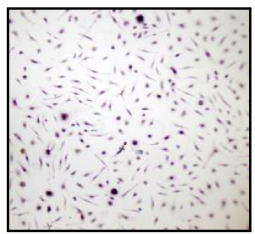

0

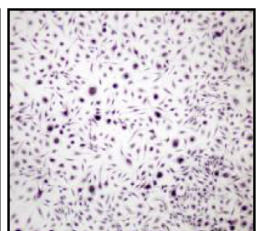

10

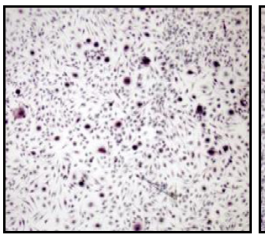

50

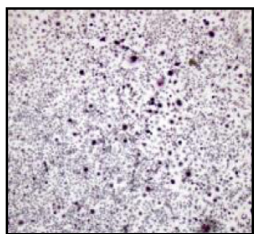

100 IL-8 (ng/mL)
B

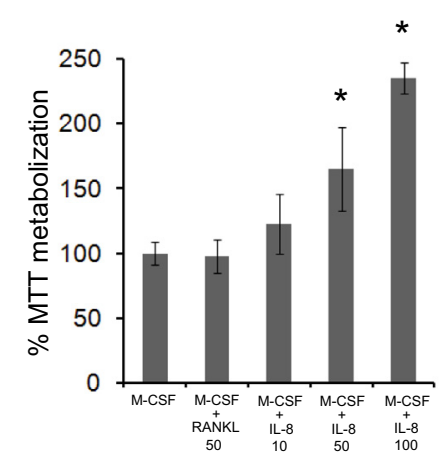

bortezomib or melphalan. Bortezomib-induced IL-8 expression was also observed in BM cells isolated from MM patients. Overexpression of IL- 8 by MM cells after treatment with lenalidomine has previously been described, ${ }^{36}$ and expression of IL- 8 has also been reported to be induced by treatment with paclitaxel in solid tumors. ${ }^{34,35} \mathrm{~A}$ recent study also found induction of IL-8 in ovarian cells by treatment with bortezomib, although this effect was not observed in HMCLs, in disagreement with our results. We speculate that the discrepancy could be related to the high concentrations of bortezomib used by Singha et al, ${ }^{47}$ which would result in MM cell death before IL-8 induction. IL-8 up-regulation by paclitaxel has been described to be mediated, at least in part, by the drug-mediated activation of NF- $\kappa \mathrm{B}$, a known inducer of IL- 6 and IL-8 expression. ${ }^{48,49}$ $\mathrm{NF}-\kappa \mathrm{B}$ activation has also been reported when MM cells were treated with melphalan, ${ }^{50}$ and also when ovarian cancer cell lines and HMCLs were treated with bortezomib, ${ }^{47,51}$ suggesting that IL-8 up-regulation induced by treatment with these two drugs in MM could also respond to $\mathrm{NF}-\kappa \mathrm{B}$ activation. Surprisingly, we found that chemical inhibition of NF- $\mathrm{NB}$ did not suppress either bortezomib- or
A

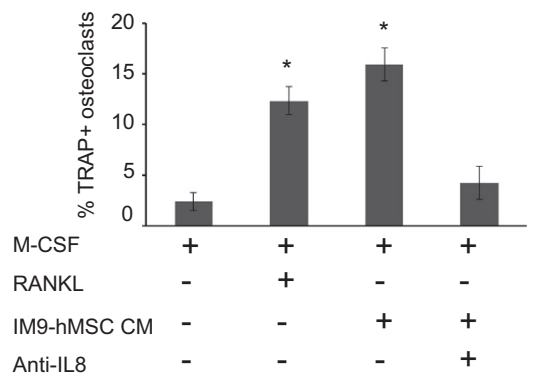

C

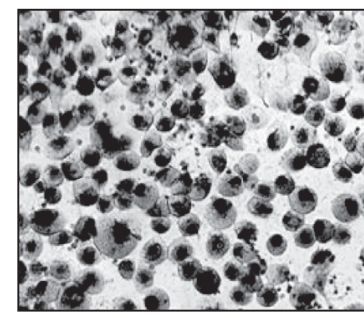

M-CSF

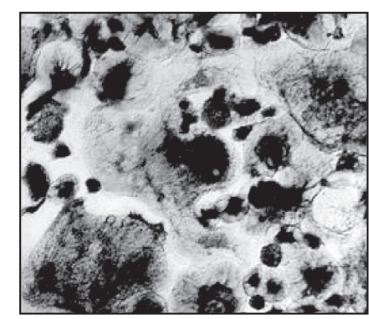

M-CSF+RANKL
B
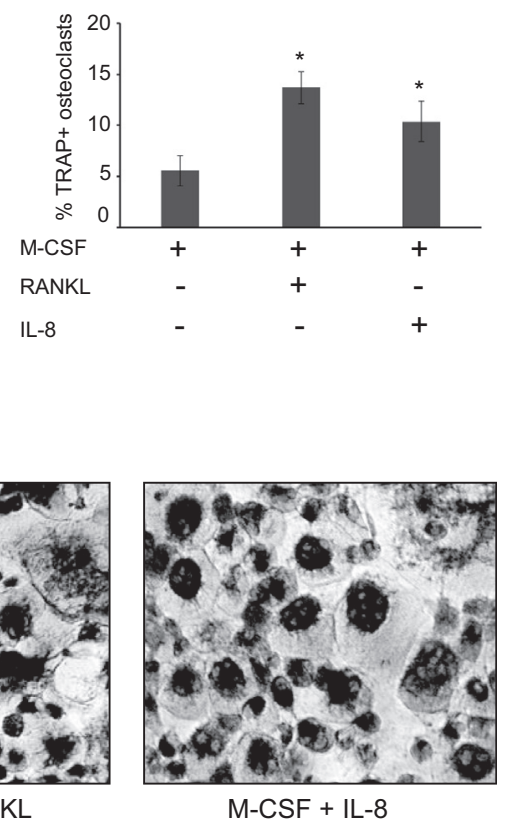

Figure 7 IL-8 induced by interactions between human myeloma cell lines and human bone marrow mesenchymal stromal cell line-TERT (hMSC-TERT) cells strongly contributes to osteoclast formation. A: Peripheral blood mononuclear cells were cultured in osteoclastogenic medium with $25 \mathrm{ng} / \mathrm{mL}$ macrophage colony-stimulating factor (M-CSF), or in the same medium containing either $50 \mathrm{ng} / \mathrm{mL}$ receptor activator of NF- $\mathrm{KB}$ ligand (RANKL) or conditioned medium (CM) from IM9-hMSC-TERT cultures at 1:4 dilution. Anti-IL-8 was added to some of the CM-containing wells. Percentage of tartrate resistance acid phosphatase $(\text { TRAP })^{+}$multinucleated cells ( $\geq 3$ nuclei) is indicated. A total of 400 cells were counted per treatment group. The experiment was performed in triplicate. B: 0steoclast formation induced by recombinant IL-8 (rIL-8) or RANKL. The experiment was performed as described in $\mathbf{A}$, but with 50 $\mathrm{ng} / \mathrm{mL}$ rIL-8. C: Representative micrographs of osteoclasts induced by RANKL or rIL-8. ${ }^{*} P<0.05$ versus wells containing only M-CSF. 
melphalan-induced IL-8 overexpression. Our results indicate that other transcriptional or post-transcriptional mechanisms must be responsible for the chemokine up-regulation in MM and highlight the fact that mechanisms governing IL-8 expression may differ among different cell types. ${ }^{47,52}$ In this regard, a recent study has reported that bortezomib induced IL-8 expression in human monocytes and macrophages through a mechanism p38 mitogen-activated protein kinase dependent and NF- $\kappa \mathrm{B}$ independent. ${ }^{53}$

We have shown that neither rIL-8 addition nor its inhibition by neutralizing antibodies affected the proliferation of HMCLs, contrary to the data reported for other tumor cell lines ${ }^{39,41-44}$ and also in MM. ${ }^{25}$ However, our results are in agreement with a previous study showing no effect of IL-8 on MM cell proliferation despite the presence of IL-8 receptors on different HMCLs. ${ }^{26}$ We observed that IL-8 clearly enhanced survival of myeloma cells in the absence of serum, as also described for IL- $6 .{ }^{13}$ Neutralizing antibodies avoided the protective effect of IL- 8 against cell death induced by serum deprivation, indirectly supporting the presence of IL-8 receptors (CXCR1/CXCR2) on HMCLs. It is possible that the signaling pathways that promote IL-8-mediated cell growth may be nonfunctional in $\mathrm{MM}$ cells, whereas those that enhance survival in the absence of growth factors could be fully operative. The effect of IL-6 in survival and protection from drug-mediated apoptosis has been attributed to the activation of JAK-STAT and phosphatidylinositol 3-kinase/Akt signaling cascades. ${ }^{1}$ However, its role in the protection of cell death induced by growth factor withdrawal has not been characterized. Herein, we showed that protection of IL-8 against cell death induced by serum deprivation did not depend on inhibition of caspase activation, in agreement with some reports that showed the existence of caspase-independent cell death under serum-free conditions. ${ }^{54,55}$ We found that IL-8 did not protect MM cells from apoptosis induced by chemotherapeutic agents. The fact that bortezomib and also melphalan induce caspase-dependent apoptosis in $\mathrm{MM}^{56,57}$ makes it tempting to speculate that IL-8 could only block myeloma apoptosis induced by caspase-independent mechanisms.

It has previously been described that rIL-8 induces osteoclast formation. ${ }^{22,23}$ In this study, we observed, first, that rIL-8 acts as a growth factor for osteoclast precursors, which could eventually differentiate to functional osteoclasts in bone-resorbing areas at sites of myeloma growth; and second, that the CM from myeloma-stromal co-cultures triggered osteoclast differentiation. Neutralization of IL-8 by the correspondent antibodies markedly reduced osteoclast formation, which revealed that the osteoclastogenic activity of the CM was mainly induced by IL- 8 . We found that rIL-8 reproduced the effect of the $\mathrm{CM}$, and directly stimulated osteoclastogenesis independent of RANKL, in agreement with previous reports. ${ }^{22,23}$

In summary, we showed that interactions between myeloma and stromal cells, and treatment with antimyeloma drugs triggered IL-8 overexpression. BM stromal cells were the major source of IL-8 in stromal-MM co-cultures. However, we cannot exclude the possibility that other cells in the BM microenvironment, in addition to stromal cells, might contribute to IL-8 production. This is in fact indirectly suggested by the high content of IL-8 in the CM of BM cultures from myeloma patients (Figure 1C), and also by the elevated serum levels of IL-8 found in MM patients. ${ }^{58,59}$ In this study, we present evidence of osteoclastogenesis promotion by IL- 8 from myeloma and stromal cultures and antiapoptotic effects of IL-8 on serum-deprived myeloma cells. These findings, together with the angiogenic and MM cell chemotactic roles of IL-8, ${ }^{25,26}$ suggest that anti-IL-8 therapy might be beneficial to prevent unwanted effects of IL-8 up-regulation because of interactions of myeloma cells with the microenvironment or treatment with antimyeloma drugs.

\section{Acknowledgments}

We thank Isabel Isidro, Teresa Prieto, and Vanesa Gutiérrez for their technical assistance in purification of MM samples; and Dr. Campana (St. Jude Children's Research Hospital, Memphis, TN) and Dr. Mitsiades (Dana-Farber Cancer Institute, Boston, MA) for hMSC-TERT and MM.1S-luc cell lines, respectively.

\section{References}

1. Mahindra A, Hideshima T, Anderson KC: Multiple myeloma: biology of the disease. Blood Rev 2010, 24(Suppl 1):S5-S11

2. San Miguel JF, Gutierrez NC, Mateo G, Orfao A: Conventional diagnostics in multiple myeloma. Eur J Cancer 2006, 42:1510-1519

3. Rajkumar SV, Dimopoulos MA, Palumbo A, Blade J, Merlini G, Mateos MV, Kumar S, Hillengass J, Kastritis E, Richardson P, Landgren O, Paiva B, Dispenzieri A, Weiss B, LeLeu X, Zweegman S, Lonial S, Rosinol L, Zamagni E, Jagannath S, Sezer O, Kristinsson SY, Caers J, Usmani SZ, Lahuerta JJ, Johnsen HE, Beksac M, Cavo M, Goldschmidt H, Terpos E, Kyle RA, Anderson KC, Durie BG, Miguel JF: International Myeloma Working Group updated criteria for the diagnosis of multiple myeloma. Lancet Oncol 2014, 15:e538-e548

4. Grigorieva I, Thomas X, Epstein J: The bone marrow stromal environment is a major factor in myeloma cell resistance to dexamethasone. Exp Hematol 1998, 26:597-603

5. Ghobrial IM: Myeloma as a model for the process of metastasis: implications for therapy. Blood 2012, 120:20-30

6. Klein B, Zhang XG, Jourdan M, Content J, Houssiau F, Aarden L, Piechaczyk M, Bataille R: Paracrine rather than autocrine regulation of myeloma-cell growth and differentiation by interleukin-6. Blood 1989, 73:517-526

7. Dankbar B, Padro T, Leo R, Feldmann B, Kropff M, Mesters RM, Serve H, Berdel WE, Kienast J: Vascular endothelial growth factor and interleukin-6 in paracrine tumor-stromal cell interactions in multiple myeloma. Blood 2000, 95:2630-2636

8. Gupta D, Treon SP, Shima Y, Hideshima T, Podar K, Tai YT, Lin B Lentzsch S, Davies FE, Chauhan D, Schlossman RL, Richardson P, Ralph P, Wu L, Payvandi F, Muller G, Stirling DI, Anderson KC: Adherence of multiple myeloma cells to bone marrow stromal cells upregulates vascular endothelial growth factor secretion: therapeutic applications. Leukemia 2001, 15:1950-1961 
9. Hideshima T, Nakamura N, Chauhan D, Anderson KC: Biologic sequelae of interleukin-6 induced PI3-K/Akt signaling in multiple myeloma. Oncogene 2001, 20:5991-6000

10. Chauhan D, Uchiyama H, Akbarali Y, Urashima M, Yamamoto K, Libermann TA, Anderson KC: Multiple myeloma cell adhesioninduced interleukin- 6 expression in bone marrow stromal cells involves activation of NF-kappa B. Blood 1996, 87:1104-1112

11. Frassanito MA, Silvestris F, Silvestris N, Cafforio P, Camarda G, Iodice G, Dammacco F: Fas/Fas ligand (FasL)-deregulated apoptosis and IL-6 insensitivity in highly malignant myeloma cells. Clin Exp Immunol 1998, 114:179-188

12. Hardin J, MacLeod S, Grigorieva I, Chang R, Barlogie B, Xiao H, Epstein J: Interleukin-6 prevents dexamethasone-induced myeloma cell death. Blood 1994, 84:3063-3070

13. Lichtenstein A, Tu Y, Fady C, Vescio R, Berenson J: Interleukin-6 inhibits apoptosis of malignant plasma cells. Cell Immunol 1995, 162:248-255

14. Yoshimura T, Matsushima K, Tanaka S, Robinson EA, Appella E, Oppenheim JJ, Leonard EJ: Purification of a human monocytederived neutrophil chemotactic factor that has peptide sequence similarity to other host defense cytokines. Proc Natl Acad Sci U S A 1987, 84:9233-9237

15. Green AR, Green VL, White MC, Speirs V: Expression of cytokine messenger RNA in normal and neoplastic human breast tissue: identification of interleukin- 8 as a potential regulatory factor in breast tumours. Int J Cancer 1997, 72:937-941

16. Waugh DJ, Wilson C: The interleukin-8 pathway in cancer. Clin Cancer Res 2008, 14:6735-6741

17. Yoneda J, Kuniyasu H, Crispens MA, Price JE, Bucana CD, Fidler IJ: Expression of angiogenesis-related genes and progression of human ovarian carcinomas in nude mice. J Natl Cancer Inst 1998, 90: 447-454

18. Bendre MS, Gaddy-Kurten D, Mon-Foote T, Akel NS, Skinner RA, Nicholas RW, Suva LJ: Expression of interleukin 8 and not parathyroid hormone-related protein by human breast cancer cells correlates with bone metastasis in vivo. Cancer Res 2002, 62:5571-5579

19. Kim SJ, Uehara H, Karashima T, McCarty M, Shih N, Fidler IJ: Expression of interleukin-8 correlates with angiogenesis, tumorigenicity, and metastasis of human prostate cancer cells implanted orthotopically in nude mice. Neoplasia 2001, 3:33-42

20. Kitadai Y, Haruma K, Sumii K, Yamamoto S, Ue T, Yokozaki H, Yasui W, Ohmoto Y, Kajiyama G, Fidler IJ, Tahara E: Expression of interleukin-8 correlates with vascularity in human gastric carcinomas. Am J Pathol 1998, 152:93-100

21. Koch AE, Polverini PJ, Kunkel SL, Harlow LA, DiPietro LA, Elner VM, Elner SG, Strieter RM: Interleukin-8 as a macrophagederived mediator of angiogenesis. Science 1992, 258:1798-1801

22. Bendre MS, Montague DC, Peery T, Akel NS, Gaddy D, Suva LJ: Interleukin-8 stimulation of osteoclastogenesis and bone resorption is a mechanism for the increased osteolysis of metastatic bone disease. Bone 2003, 33:28-37

23. Bendre MS, Margulies AG, Walser B, Akel NS, Bhattacharrya S, Skinner RA, Swain F, Ramani V, Mohammad KS, Wessner LL, Martinez A, Guise TA, Chirgwin JM, Gaddy D, Suva LJ: Tumorderived interleukin-8 stimulates osteolysis independent of the receptor activator of nuclear factor-kappaB ligand pathway. Cancer Res 2005, 65:11001-11009

24. Merico F, Bergui L, Gregoretti MG, Ghia P, Aimo G, Lindley IJ, Caligaris-Cappio F: Cytokines involved in the progression of multiple myeloma. Clin Exp Immunol 1993, 92:27-31

25. Pellegrino A, Ria R, Di Pietro G, Cirulli T, Surico G, Pennisi A, Morabito F, Ribatti D, Vacca A: Bone marrow endothelial cells in multiple myeloma secrete CXC-chemokines that mediate interactions with plasma cells. Br J Haematol 2005, 129:248-256

26. Kline M, Donovan K, Wellik L, Lust C, Jin W, Moon-Tasson L, Xiong Y, Witzig TE, Kumar S, Rajkumar SV, Lust JA: Cytokine and chemokine profiles in multiple myeloma: significance of stromal interaction and correlation of IL-8 production with disease progression. Leuk Res 2007, 31:591-598

27. Mihara K, Imai C, Coustan-Smith E, Dome JS, Dominici M, Vanin E, Campana D: Development and functional characterization of human bone marrow mesenchymal cells immortalized by enforced expression of telomerase. Br J Haematol 2003, 120:846-849

28. Garcia-Gomez A, Quwaider D, Canavese M, Ocio EM, Tian Z, Blanco JF, Berger AJ, Ortiz-de-Solorzano C, Hernandez-Iglesias T, Martens AC, Groen RW, Mateo-Urdiales J, Fraile S, Galarraga M, Chauhan D, San Miguel JF, Raje N, Garayoa M: Preclinical activity of the oral proteasome inhibitor MLN9708 in Myeloma bone disease. Clin Cancer Res 2014, 20:1542-1554

29. Lopez-Corral L, Corchete LA, Sarasquete ME, Mateos MV, GarciaSanz R, Ferminan E, Lahuerta JJ, Blade J, Oriol A, Teruel AI, Martino ML, Hernandez J, Hernandez-Rivas JM, Burguillo FJ, San Miguel JF, Gutierrez NC: Transcriptome analysis reveals molecular profiles associated with evolving steps of monoclonal gammopathies. Haematologica 2014, 99:1365-1372

30. Fukumura D, Xavier R, Sugiura T, Chen Y, Park EC, Lu N, Selig M, Nielsen G, Taksir T, Jain RK, Seed B: Tumor induction of VEGF promoter activity in stromal cells. Cell 1998, 94:715-725

31. Nakamura $T$, Aikawa $T$, Iwamoto-Enomoto $M$, Iwamoto $M$, Higuchi Y, Pacifici M, Kinto N, Yamaguchi A, Noji S, Kurisu K, Matsuya T: Induction of osteogenic differentiation by hedgehog proteins. Biochem Biophys Res Commun 1997, 237:465-469

32. Karadag A, Oyajobi BO, Apperley JF, Russell RG, Croucher PI: Human myeloma cells promote the production of interleukin 6 by primary human osteoblasts. Br J Haematol 2000, 108:383-390

33. Hideshima T, Chauhan D, Richardson P, Mitsiades C, Mitsiades N, Hayashi T, Munshi N, Dang L, Castro A, Palombella V, Adams J, Anderson KC: NF-kappa B as a therapeutic target in multiple myeloma. J Biol Chem 2002, 277:16639-16647

34. Collins TS, Lee LF, Ting JP: Paclitaxel up-regulates interleukin- 8 synthesis in human lung carcinoma through an NF-kappaB- and AP1-dependent mechanism. Cancer Immunol Immunother 2000, 49: 78-84

35. Wang TH, Chan YH, Chen CW, Kung WH, Lee YS, Wang ST, Chang TC, Wang HS: Paclitaxel (Taxol) upregulates expression of functional interleukin-6 in human ovarian cancer cells through multiple signaling pathways. Oncogene 2006, 25:4857-4866

36. Maiga S, Gomez-Bougie P, Bonnaud S, Gratas C, Moreau P, Le Gouill S, Pellat-Deceunynck C, Amiot M: Paradoxical effect of lenalidomide on cytokine/growth factor profiles in multiple myeloma. Br J Cancer 2013, 108:1801-1806

37. Gasparian AV, Guryanova OA, Chebotaev DV, Shishkin AA, Yemelyanov AY, Budunova IV: Targeting transcription factor NFkappaB: comparative analysis of proteasome and IKK inhibitors. Cell Cycle 2009, 8:1559-1566

38. Mori N, Yamada Y, Ikeda S, Yamasaki Y, Tsukasaki K, Tanaka Y, Tomonaga M, Yamamoto N, Fujii M: Bay 11-7082 inhibits transcription factor NF-kappaB and induces apoptosis of HTLV-Iinfected T-cell lines and primary adult T-cell leukemia cells. Blood 2002, 100:1828-1834

39. Brew R, Erikson JS, West DC, Kinsella AR, Slavin J, Christmas SE: Interleukin- 8 as an autocrine growth factor for human colon carcinoma cells in vitro. Cytokine 2000, 12:78-85

40. Li A, Varney ML, Valasek J, Godfrey M, Dave BJ, Singh RK: Autocrine role of interleukin-8 in induction of endothelial cell proliferation, survival, migration and MMP-2 production and angiogenesis. Angiogenesis 2005, 8:63-71

41. Metzner B, Hofmann C, Heinemann C, Zimpfer U, Schraufstatter I, Schopf E, Norgauer J: Overexpression of CXC-chemokines and CXC-chemokine receptor type II constitute an autocrine growth mechanism in the epidermoid carcinoma cells KB and A431. Oncol Rep 1999, 6:1405-1410

42. Miyamoto M, Shimizu Y, Okada K, Kashii Y, Higuchi K, Watanabe A: Effect of interleukin-8 on production of tumor-associated 
substances and autocrine growth of human liver and pancreatic cancer cells. Cancer Immunol Immunother 1998, 47:47-57

43. Singh S, Singh AP, Sharma B, Owen LB, Singh RK: CXCL8 and its cognate receptors in melanoma progression and metastasis. Future Oncol 2010, 6:111-116

44. Takamori H, Oades ZG, Hoch OC, Burger M, Schraufstatter IU: Autocrine growth effect of IL-8 and GROalpha on a human pancreatic cancer cell line, Capan-1. Pancreas 2000, 21:52-56

45. Munshi NC, Hideshima T, Carrasco D, Shammas M, Auclair D, Davies F, Mitsiades N, Mitsiades C, Kim RS, Li C, Rajkumar SV, Fonseca R, Bergsagel L, Chauhan D, Anderson KC: Identification of genes modulated in multiple myeloma using genetically identical twin samples. Blood 2004, 103:1799-1806

46. Anderson IC, Mari SE, Broderick RJ, Mari BP, Shipp MA: The angiogenic factor interleukin 8 is induced in non-small cell lung cancer/pulmonary fibroblast cocultures. Cancer Res 2000, 60:269-272

47. Singha B, Gatla HR, Manna S, Chang TP, Sanacora S, Poltoratsky V, Vancura A, Vancurova I: Proteasome inhibition increases recruitment of IkappaB kinase beta (IKKbeta), S536P-p65, and transcription factor EGR1 to interleukin-8 (IL-8) promoter, resulting in increased IL-8 production in ovarian cancer cells. J Biol Chem 2014, 289:2687-2700

48. Libermann TA, Baltimore D: Activation of interleukin-6 gene expression through the NF-kappa B transcription factor. Mol Cell Biol 1990, 10:2327-2334

49. Yuan A, Chen JJ, Yao PL, Yang PC: The role of interleukin-8 in cancer cells and microenvironment interaction. Front Biosci 2005, 10:853-865

50. Baumann P, Mandl-Weber S, Oduncu F, Schmidmaier R: Alkylating agents induce activation of NFkappaB in multiple myeloma cells. Leuk Res 2008, 32:1144-1147

51. Hideshima T, Ikeda H, Chauhan D, Okawa Y, Raje N, Podar K, Mitsiades C, Munshi NC, Richardson PG, Carrasco RD, Anderson KC: Bortezomib induces canonical nuclear factor-kappaB activation in multiple myeloma cells. Blood 2009, 114:1046-1052
52. Hoffmann E, Dittrich-Breiholz O, Holtmann H, Kracht M: Multiple control of interleukin-8 gene expression. J Leukoc Biol 2002, 72: 847-855

53. Sanacora S, Urdinez J, Chang TP, Vancurova I: Anticancer drug bortezomib increases interleukin-8 expression in human monocytes. Biochem Biophys Res Commun 2015, 460:375-379

54. Hamabe W, Fukushima N, Yoshida A, Ueda H: Serum-free induced neuronal apoptosis-like cell death is independent of caspase activity. Brain Res Mol Brain Res 2000, 78:186-191

55. Joza N, Susin SA, Daugas E, Stanford WL, Cho SK, Li CY, Sasaki T, Elia AJ, Cheng HY, Ravagnan L, Ferri KF, Zamzami N, Wakeham A, Hakem R, Yoshida H, Kong YY, Mak TW, ZunigaPflucker JC, Kroemer G, Penninger JM: Essential role of the mitochondrial apoptosis-inducing factor in programmed cell death. Nature 2001, 410:549-554

56. Podar K, Gouill SL, Zhang J, Opferman JT, Zorn E, Tai YT, Hideshima T, Amiot M, Chauhan D, Harousseau JL, Anderson KC: A pivotal role for Mcl-1 in Bortezomib-induced apoptosis. Oncogene 2008, 27:721-731

57. Gomez-Bougie P, Oliver L, Le Gouill S, Bataille R, Amiot M: Melphalan-induced apoptosis in multiple myeloma cells is associated with a cleavage of Mcl-1 and Bim and a decrease in the Mcl-1/Bim complex. Oncogene 2005, 24:8076-8079

58. Tsirakis G, Pappa CA, Kaparou M, Katsomitrou V, Hatzivasili A, Alegakis T, Xekalou A, Stathopoulos EN, Alexandrakis MG: Assessment of proliferating cell nuclear antigen and its relationship with proinflammatory cytokines and parameters of disease activity in multiple myeloma patients. Eur J Histochem 2011, 55:e21

59. Pappa CA, Tsirakis G, Kanellou P, Kaparou M, Stratinaki M, Xekalou A, Alegakis A, Boula A, Stathopoulos EN, Alexandrakis MG: Monitoring serum levels ELR + CXC chemokines and the relationship between microvessel density and angiogenic growth factors in multiple myeloma. Cytokine 2011, 56:616-620 